\title{
Reuse of Chicken Eggshell Ash and Natural Zeolite Catalyst on Palm Oil Transesterification
}

\author{
Taslim*, Iriany, Mawaddah Nur Tambak, and Okta Bani \\ Department of Chemical Engineering, Faculty of Engineering, Universitas Sumatera Utara, Medan 20155, Indonesia.
}

ORCIDs: 0000-0003-0482-320X (Taslim), 0000-0001-8963-551X (Iriany)

\begin{abstract}
A study on reuse of catalyst based on combination of chicken eggshells ash and natural zeolite on palm oil transesterification has been investigated. The transesterification was performed at $65^{\circ} \mathrm{C}$, reaction time of 3 hours, palm oil to methanol molar ratio (OMR) of 1:12, and catalyst load of $8 \%$. The catalyst was regenerated before each reuse. Regeneration was carried out by washing the catalyst using a solvent (methanol, ethanol or n-hexane) at catalyst to solvents ratio (CSR) of 1:3 to $1: 6(\mathrm{w} / \mathrm{v})$, followed by drying. The test results indicated that catalyst washed by $n$-hexane at CSR of 1:6 gave the best results and can be reused three times with a consecutive biodiesel yield of 96.8, 94.8, and 91.3\%.
\end{abstract}

Keywords: calcination, chicken eggshell ash, natural zeolite, transesterification, biodiesel yield

\section{INTRODUCTION}

Biodiesel production attracts attention because it is a renewable, clean and non-toxic fuel. Biodiesel can be synthesized from vegetable oils or animal fats through transesterification. Generally, transesterification requires a catalyst to increase the reaction rate. Both homogeneous and heterogeneous catalysts can be used in biodiesel formation. However, homogeneous catalysts may cause saponification and complicate product separation so that the cost of biodiesel production is expensive. To overcome this problem, heterogeneous catalysts are used instead. The advantage of heterogeneous catalysts is that they are easily separated from the reaction mixture, do not produce soap, have high catalyst activity during the reaction, can be reused and are environmentally friendly [1]. In addition, heterogeneous catalysts can be obtained from renewable natural resources, such as chicken eggshell waste, crab shell waste, shellfish waste and animal bone waste [2].

One of the heterogeneous catalysts is the calcium oxide $(\mathrm{CaO})$ catalyst which is easily found in nature. $\mathrm{CaO}$ can be synthesized from several natural calcium sources such as chicken eggshell [3]. Chicken eggshell contains $96 \%$ calcium carbonate $\left(\mathrm{CaCO}_{3}\right)$. These carbonate compounds are calcined at high temperatures to produce chicken eggshell ash (CEA) whose main composition is $\mathrm{CaO}[3,4]$. $\mathrm{CaO}$ has been used as catalysts in transesterification [4,5,6]. However, this catalyst is susceptible to poisoning and leaching [7]. Adding a buffer such as natural zeolite (NZ) to CEA can overcome these problems and can increase the catalytic ability of CEA [3]. In addition to acting as a CEA buffer, NZ itself has the ability to support $\mathrm{Na}_{2} \mathrm{CO}_{3}$ and $\mathrm{KOH}$ catalysts $[8,9]$.

Selection of heterogeneous catalysts in transesterification is usually based on their catalytic activity, reusability, ecofriendliness and cost. After usage, catalyst can be regenerated by using specific treatment. Usually, upon completion of transesterification, catalyst is separated from the product mixture by means of filtration or centrifugation, followed by washing with solvents such as methanol, ethanol, and nhexane to remove the remaining organic impurities on catalyst surface [10] and then dried.

The reuse (recyclability) of CEA/NZ catalysts in transesterification has never been reported. Therefore, this study aimed to evaluate catalyst regeneration using several solvents, and its performance with each reuses.

\section{MATERIALS AND METHODS}

\section{II.I. MATERIALS}

In this study, CEA was used as $\mathrm{CaO}$ source. CEA was obtained from a restaurant at Setia Budi street, Medan. NZ was obtained from Tapanuli, North Sumatera. Chemicals such as methanol, ethanol, and n-hexane were purchased from RJ chemical store, Medan. Palm oil was obtained from local producer in North Sumatera.

\section{II.II. METHODS}

This study was composed of catalyst preparation, transesterification, and catalyst regeneration.

\section{II.II.I. Catalyst preparation}

The catalyst preparation procedure was done according to Taslim et al. [3]. First, prewashed chicken eggshell was dried in oven at $110^{\circ} \mathrm{C}$ for $4 \mathrm{~h}$, then calcined at $1000^{\circ} \mathrm{C}$ for 2 hours. CEA formed, after cooled to room temperature, was sieved to 
200 meshes. Meanwhile, NZ of 200 meshes was also prepared. CEA and NA were then mixed at a weight ratio of $1: 3$, and stored in tightly closed plastic containers and ready to be used as a catalyst in transesterification. Catalyst analysis before and after transesterification was carried out using SEM-EDX.

\section{II.II.II. Transesterification}

Transesterification of palm oil and methanol was carried out in a three neck flask at $65^{\circ} \mathrm{C}$ for $3 \mathrm{~h}$. The molar ratio of palm oil to methanol (OMR) was 1:12, catalyst load was $8 \%(w / w)$ and stirring rate was $700 \mathrm{rpm}$ [3]. The flask was equipped with a heater, stirrer, thermometer and condenser. Upon completion, products were separated from the catalyst by filtration. The filtrate (crude methyl ester and glycerol) was purified following procedure informed by Taslim et al 2020 [3]. The biodiesel obtained was analyzed for its density, viscosity, and methyl ester purity (MEP).

\section{II.II. III. Catalyst regeneration}

The filtration cake was washed using several different solvents (methanol, ethanol, and n-hexane). The catalyst to solvent ratio (CSR) was varied from 1:3, 1:4, 1:5, and 1:6 $(\mathrm{w} / \mathrm{v})$. The catalyst and solvent was mixed and stirred at 300 rpm for $30 \mathrm{~min}$, then separated using Whatman filter paper no. 41. The washed catalyst was dried in the oven at $130^{\circ} \mathrm{C}$ for $24 \mathrm{~h}$.

\section{RESULTS AND DISCUSSION}

\section{III.I. CATALYST CHARACTERIZATION}

\section{III.I.I. SEM analysis}

In this study, SEM analysis was performed to observe the morphology of CEA, NZ and CEA/NA catalyst. In fig 1, CEA has structured and uniform surface. In fig 2, NZ has sharp irregular surface.

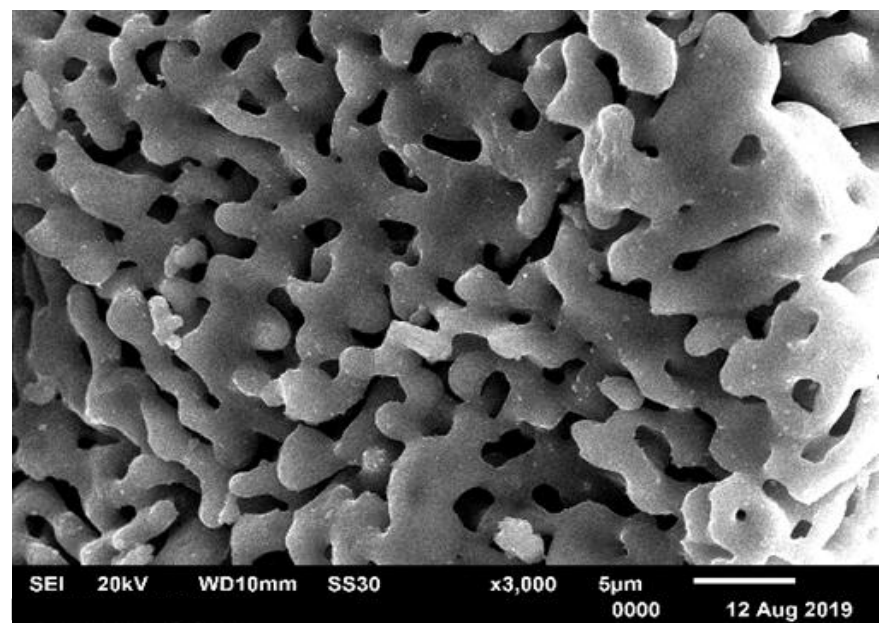

Fig 1. SEM result of CEA at 3000x magnification

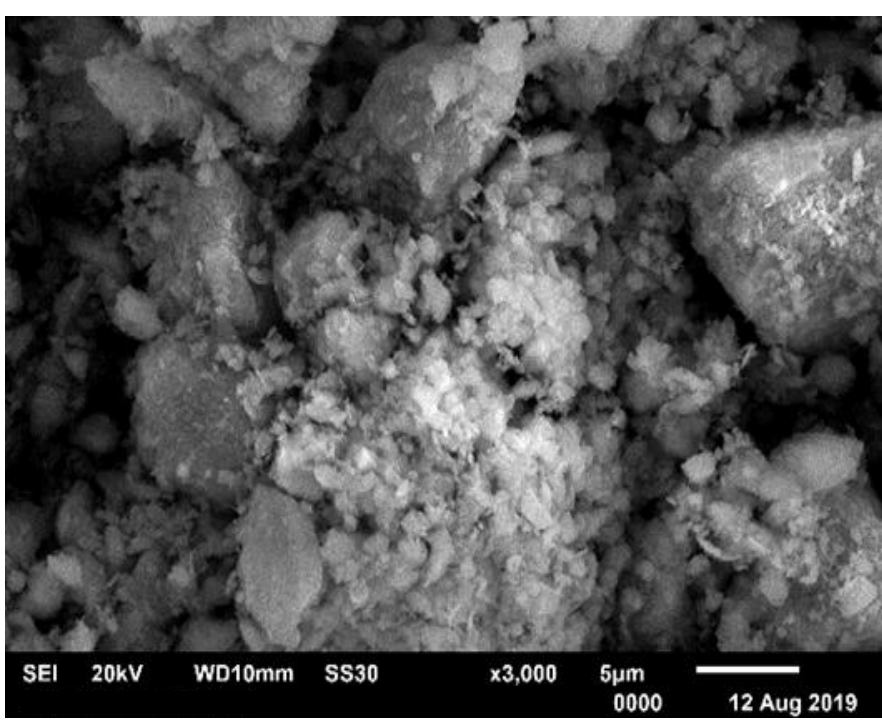

Fig 2. SEM result of NZ at 3000x magnification

Fig 3 displays the fresh CEA/NZ catalyst mix at a fixed weight ratio of $1: 3$. The fresh $\mathrm{CEA} / \mathrm{NZ}$ catalyst contained CEA dispersed on surface and pore of NZ. This catalyst mixture had a size of 1-20 $\mu \mathrm{m}$. It was applied in transesterification then reused.

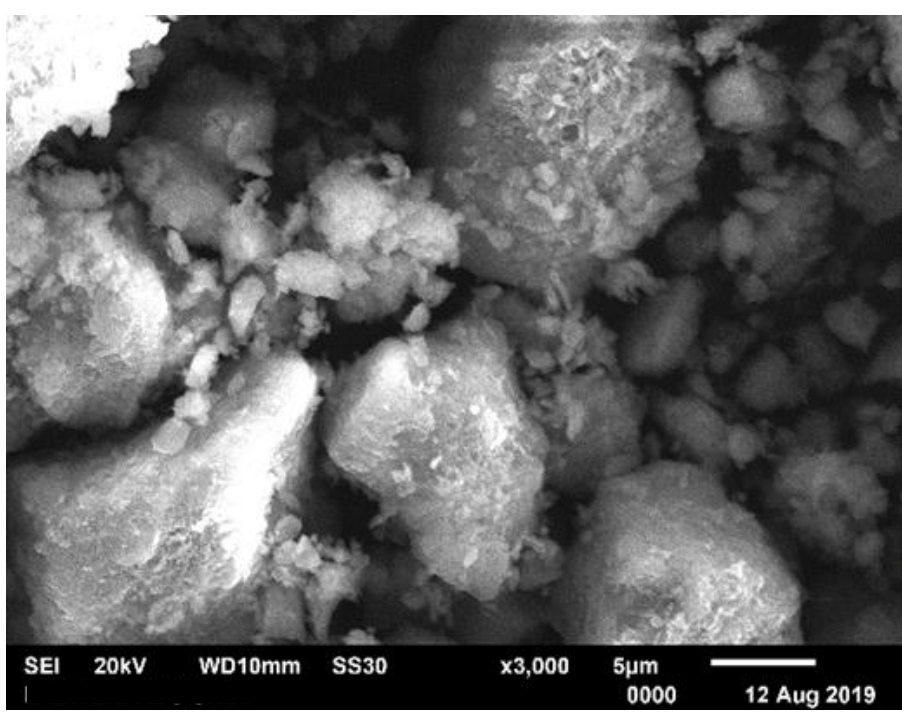

Fig 3. SEM result of fresh CEA/NZ catalyst at 3000x magnification

Fig 4 shows the catalyst surface appeared to be flatter with fewer pores, due to being covered with dirt. The catalyst had been used three times and washed using n-hexane at CSR of 1:6 (w/v). Solid catalysts that have been used repeatedly in biodiesel production can undergo structural changes on the catalyst surface which can reduce catalyst activity because it is surrounded by products that can block contact between catalyst and reactants [10]. 


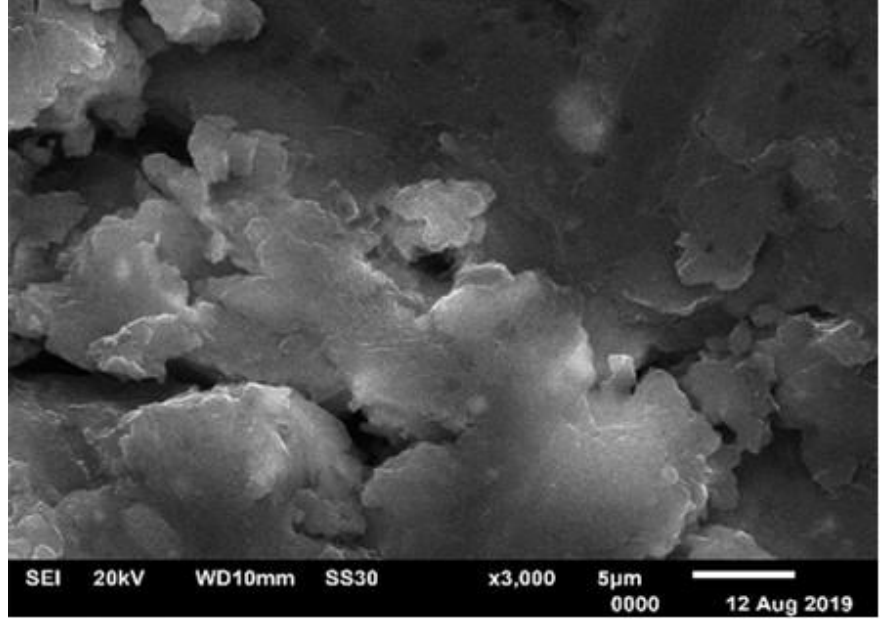

Fig 4. SEM result of CEA/NA catalyst after 3 times usage at 3000x magnfication

\section{III.I.II. EDX analysis}

Composition of CEA/NZ catalyst was analyzed using EDX as part of SEM-EDX analysis and presented in table 1.

Table 1. Percentage of CEA/NZ catalyst composition
Component Before regeneration

$(\%)$

After regeneration

$(\%)$

$\begin{array}{ccc}\mathrm{C} & 18.08 & 87.23 \\ \mathrm{SiO}_{2} & 53.55 & 5.85 \\ \mathrm{Al}_{2} \mathrm{O}_{3} & 10.66 & 1.16 \\ \mathrm{~K}_{2} \mathrm{O} & 3.12 & 0.36 \\ \mathrm{Na}_{2} \mathrm{O} & 1.19 & 0.00 \\ \mathrm{MgO} & 0.68 & 0.29 \\ \mathrm{CaO} & 9.75 & 5.11 \\ \mathrm{FeO} & 1.61 & 0.00 \\ \mathrm{CuO} & 1.36 & 0.00\end{array}$

In Table 1, carbon percentage increased from $18.08 \%$ to $87.23 \%$. The increase in element $\mathrm{C}$ was probably due to the organic impurities on the catalyst. Other compounds $\left(\mathrm{SiO}_{2}\right.$, $\mathrm{Al}_{2} \mathrm{O}_{3}, \mathrm{~K}_{2} \mathrm{O}, \mathrm{Na}_{2} \mathrm{O}, \mathrm{MgO}, \mathrm{CaO}, \mathrm{FeO}$, and $\mathrm{CuO}$ ) percentage decreased after catalyst reuse in transesterification. Similar finding was also reported by some researches, which stated that repeated transesterification could result in loss of base sites on the catalyst $[11,12]$.

\section{III.II. CATALYST RECYCLABILITY}

III.II.I. Effect of catalyst weight to solvent volume ratio (CSR) on biodiesel yield

To understand the effect of CSR on biodiesel yield, waste
CEA/NZ catalyst was regenerated using methanol after application in palm oil transesterification, and reapplied in transesterification at similar condition. Methanol was chosen as the benchmark solvent because it is widely implemented to wash used catalysts $[10,13]$. In fig 5, CSR of 1:3 produced $59.2 \%$ biodiesel yield. At that ratio, methanol is unable to achieve satisfactory oil and impurities dissolution on catalyst surface. As a result, the catalyst is still bounded by materials that block contact between reactants and catalyst, and biodiesel yield is low. At higher ratios of $1: 4 ; 1: 5$ and 1:6, biodiesel yield was $67.8,84.2$ and $93.1 \%$, respectively.

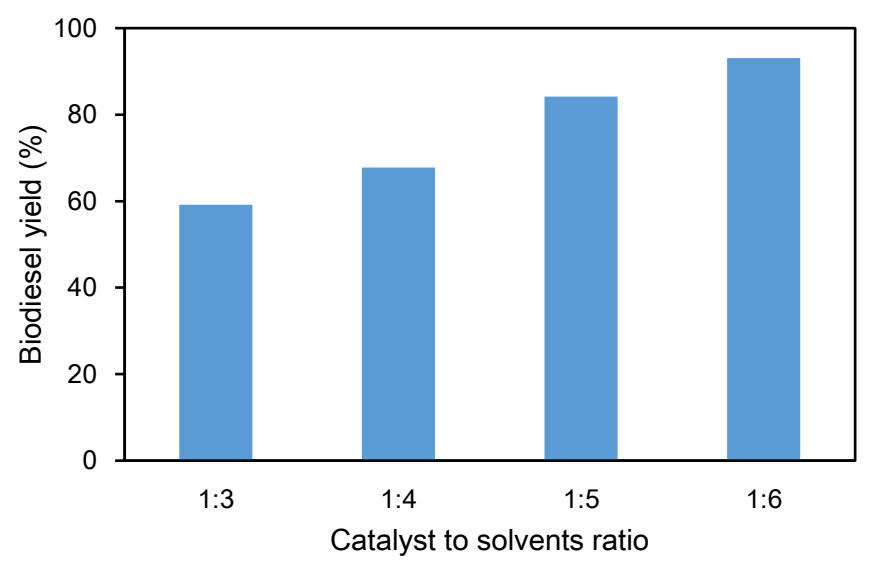

Fig 5. Effect of CSR on biodiesel yield

This finding indicates that more solvent will washed off more remaining oil and organic impurities on catalyst surface, allowing better contact between catalyst and reactants, and higher yields. In fig 5, CSR of 1:6 gave highest biodiesel yield at $93.1 \%$. Product purity obtained was $97.1 \%$.

III.II.II. Effect of solvent type on biodiesel yield

The effect of solvent type on biodiesel yield during regeneration was performed at CSR of 1:6 as displayed in fig 6. The use of methanol for catalyst regeneration yielded $93.1 \%$ biodiesel at $97.1 \%$ MEP. While, ethanol yielded $74.4 \%$ biodiesel at $81.7 \% \mathrm{MEP}$ and n-hexane yielded $94.8 \%$ biodiesel at $97.8 \% \mathrm{MEP}$.

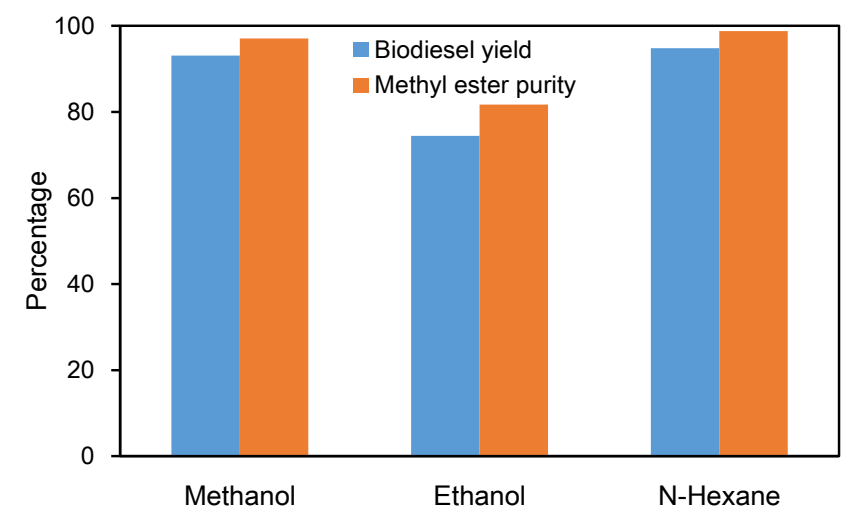

Fig 6. Effect of solvent type on methyl ester yield and purity at CSR of $1: 6$ 
In fig 6, n-hexane gave highest methyl ester yield and purity. $\mathrm{N}$-hexane is a non-polar organic liquid, and such, it performs better than methanol and ethanol at liberating oil from catalyst surface. There are also differences in oil solubility of each solvent. Oil is not soluble in water but soluble in organic solvents and non-polar organic solvents. Oil can dissolve in a solvent because oil has the same polarity as the solvent [14]. The results confirmed that n-hexane is applicable as CEA/NZ catalyst washer in biodiesel production. This finding is also consistent with literature in which hexane is a widely used solvent to dissolve oil [15].

\section{III.II.III. Effect of catalyst reuse on biodiesel yield}

In fig 7 , catalyst reuse degrades biodiesel yield with each cycle. In this study, the initial biodiesel yield was $96.8 \%$ for fresh catalyst. At second use, the yield was 94.8\%. It was $91.3 \%$ at third use and $86.7 \%$ at fourth use. The reduction in catalytic activity is mainly due to structural modifies on catalyst surface, in which the surface appeared to be flatter with fewer pores due to dirt coverage. In addition, catalyst regeneration using a solvent can reduce the amount of metal oxides or base sites. However, heterogeneous catalysts can still be reused several times under proper treatment.

MEP also declines after each catalyst reuse. MEP obtained using catalyst at first to third uses is 98.8, 97.8 and 96.9, respectively. Although biodiesel yield drops fairly quickly with repeated reuse of the catalyst, MEP is still $\geq 96.5 \%$ after three uses. However, at fourth use MEP dropped to $94.8 \%$.
This MEP value is below the minimum requirement of $96.5 \%$. The results obtained from this research confirmed that the $\mathrm{CEA} / \mathrm{NZ}$ catalyst can only be reused up to three times.

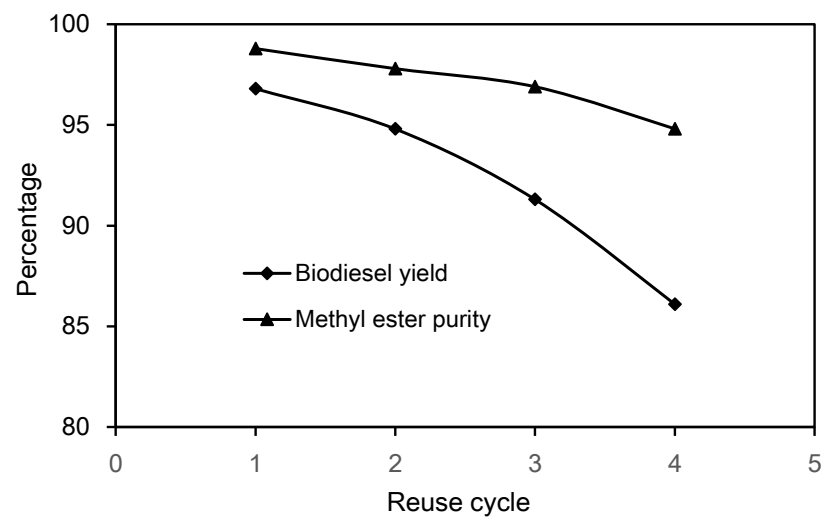

Fig 7. Effect of catalyst reuse on MEP at CSR of 1:6

\section{III.II.III. Biodiesel properties}

The physical properties of biodiesel with best results obtained in this study, which was obtained using n-hexane at CSR of 1:6, is compared to European Standards (EN 14214). The comparisons are presented in table 2 . In table 2, biodiesel produced in this study up to three times reuse has met the requirements of existing standards.

Table 2. Comparison of biodiesel properties with EN 14214

\begin{tabular}{|c|c|c|c|c|c|c|}
\hline \multirow{2}{*}{ Parameter } & \multirow{2}{*}{ Unit } & \multicolumn{4}{|c|}{ Biodiesel properties obtained for each catalyst cycle } & \multirow{2}{*}{ EN14214 } \\
\hline & & $1^{\text {st }}$ & $2^{\text {nd }}$ & $3^{\text {rd }}$ & $4^{\text {th }}$ & \\
\hline Ester purity & $\% \mathrm{w} / \mathrm{w}$ & 98.8 & 97.8 & 96.9 & 94.8 & $\geq 96.5$ \\
\hline Density & $\mathrm{kg} / \mathrm{m}^{3}$ & 886 & 864 & 875 & 888 & $860-900$ \\
\hline Monoglyceride & $\% \mathrm{w} / \mathrm{w}$ & 0.030 & 0.043 & 0.052 & 0.065 & $\leq 0.80$ \\
\hline Diglyceride & $\% \mathrm{w} / \mathrm{w}$ & 0 & 0.073 & 0.098 & 0.135 & $\leq 0,20$ \\
\hline Triglyceride & $\% \mathrm{w} / \mathrm{w}$ & 0 & 0.125 & 0.168 & 0.189 & $\leq 0,20$ \\
\hline Kinematic viscosity & $\mathrm{mm} / \mathrm{s}^{2}$ & 4.2 & 4.6 & 4.8 & 5.1 & $3.5-5.0$ \\
\hline
\end{tabular}

\section{CONCLUSION}

CEA/NZ catalyst can be used several times in transesterification after regeneration. In this study, the best solvent for the catalyst regeneration was n-hexane, at CSR of 1:6. During regeneration, base sites of the catalyst may decline, resulting in loss of catalytic activity. However, $\mathrm{CEA} / \mathrm{NZ}$ catalyst still yielded satisfactory results up to three times reuse.

\section{REFERENCES}

[1] S. Boonyuen, S.M. Smith, M. Malaithong, A. Prokaew, B. Cherdhirunkorn, and A. Luengnaruemitchai, Biodiesel production by a renewable catalyst from calcined Turbo jourdani (Gastropoda: Turbinidae) shells. Journal of Cleaner Production, 177, 2018, 925929.

[2] B. Sanjay, Heterogeneous catalyst derived from natural 
resources for biodiesel production: A review. Research Journal of Chemical Sciences, 3 (6), 2013, 95-101.

[3] Taslim, N. Taruna, Meilia, Iriany, and O. Bani, Biodiesel formation via the transesterification of treated waste cooking oil using chicken eggshells ash and natural zeolite as solid catalyst, International Journal of Engineering Research and Technology, 13 (3), 2020, 433-437

[4] Y.H. Tan, M.O. Abdullah, C.N. Hipolito, and Y.H.T.Yap, Waste ostrich and chicken-eggshells as heterogeneous base catalyst for biodiesel production from used cooking oil: catalyst characterization and biodiesel yield performance, Applied Energy, 160, 2015, 58-70.

[5] E. Fayyazi, B. Ghobadian, H.H. van de Bovenkamp, G. Najafi, B. Hosseinzadehsamani, H.J. Heeres, and J. Yue, Optimization of biodiesel production over chicken eggshell-derived $\mathrm{CaO}$ catalyst in a continuous centrifugal contactor separator, Industrial \& Engineering Chemistry Research, 57, 2018, 1274212755.

[6] M. Verziu, S.M. Coman, R. Richards, and V.I. Parvulescu, Transesterification of vegetable oils over CaO catalyst, Catalyst Today, 167, 2011, 64-70.

[7] D.M. Marinkovic, M.V. Stankovic, A.V. Velickovic, J.M. Avramovic, M.R. Miladinovic, O.O. Stamenkovic, V.B. Veljkovic, and D.M. Jovanovic, Calcium oxide as a promising heterogenous catalyst for biodiesel production: Current state and perspectives. Renewable and Sustainable Energy Reviews, 56, 2016, 1387-1408.

[8] Taslim, Iriany, O. Bani, S.Z.D.M. Parinduri, and P.R.W. Ningsih, 2018, Biodiesel production from rice bran oil using heterogeneous catalyst natural zeolite modified with $\mathrm{K}_{2} \mathrm{CO}_{3}$, IOP Conf. Series: Materials Science and Engineering, 309, 012107.

[9] Taslim, Iriany, O. Bani, S.Z.D.M. Parinduri, P.R.W. Ningsih, Preparation, characterization and application of natural zeolite from Tapanuli Indonesia modified with $\mathrm{KOH}$ as catalyst support for transesterification of rice bran oil, International Journal of Engineering Research and Technology, 12 (9), 2019, 1452-1456.

[10] H. Sun, Y. Ding, J. Duan, Q. Zhang, Z. Wang, H. Lou, and $\mathrm{X}$. Zheng, Transesterification of sunflower oil to biodiesel on $\mathrm{ZrO}_{2}$ supported $\mathrm{La}_{2} \mathrm{O}_{3}$ catalyst. Bioresource Technology, 101, 2010, 953-958.

[11] P.B. Zhang, Q.J. Han, M.M. Fan, and P.P. Jiang, Magnetic solid base catalyst $\mathrm{CaO} / \mathrm{CoFe}_{2} \mathrm{O}_{4}$ for biodiesel production: influence of basicity and wettability of the catalyst in catalytic performance. Appl Surf Sci., 317, 2014, 1125-30.

[12] M. Kouzu and J.S., Hidaka Purification to remove leached $\mathrm{CaO}$ catalyst from biodiesel with the help of cation-exchange resin, Fuel, 105, 2013, 318-324.

[13] S. Alaei, M. Haghighi, J. Toghiani, and B. R. Vahid, Magnetic and reusable $\mathrm{MgO} / \mathrm{MgFe}_{2} \mathrm{O}_{4}$ nanocatalyst for biodiesel production from sunflower oil: influence of fuel ratio in combustion synthesis on catalytic properties and performance. Industrial Crops \& Products, 117, 2018, 322-332.

[14] M. Bockisch, 1998. Fats and Oils Handbook. Germany: AOCS Press

[15] E. Bernardini, 1985. Oil Seeds, Oils and Fats. Vol.2. $2^{\text {nd }}$ Edition. Rome: B.E Oil Publishing House. 